\title{
Green Purchasing from the Perspective of Consumer Trade Off: The Moderating Effect of Urban Hierarchy
}

\author{
Xiuli Hu \\ School of Economics \& Management, Southwest University of Science and Technology, Mianyang 621010, China
}

\begin{abstract}
Guiding consumers to make green purchases is the key to building an ecological civilization and a beautiful China. Based on the theory of planned behavior, this paper constructs a theoretical model of consumers' benefit-risk green purchase behavior. Through questionnaire survey, structural equation model and grouping regression, this paper discusses the impact of perceived benefits and perceived risk on green purchase behavior, and verifies the regulatory effect of city level on consumers green purchase behavior. The results show that functional value, social value, emotional value and environmental value have a significant positive impact on green purchase attitude, and emotional value is the greatest driving force; Economic risk, time risk and functional risk can significantly promote green purchase attitude, and time risk is the most significant. In addition, the grouping regression results show that the city level has a regulatory effect between functional value, social value, emotional value, time risk, functional risk and purchase attitude, but the regulatory effect between environmental value, economic risk and purchase attitude is not significant.
\end{abstract}

Keywords: Green purchase, Perceived value, Perceived risk, City level, Structural equation.

\section{Introduction}

While industrialization and urbanization are rapidly promoting the improvement of human quality of life, they also bring problems such as energy consumption and environmental pollution. One of the important reasons for these problems is unreasonable consumption habits and consumption patterns. Therefore, how to change their consumption concept, guide consumers to give up the consumption habit of waste and show off, and actively participate in environmental protection and healthy green consumption has become the top priority. Although China has issued a series of policies to promote green consumption, for example, the 19th National Congress emphasized promoting green development and the 14th five year plan pointed out that green consumption and lifestyle should be placed in a more prominent strategic position; The national development and Reform Commission has indicated that people should be actively guided to practice green lifestyles and consumption patterns. However, green consumption is still in the primary stage of exploration in China. In practice, consumers' willingness to buy green products is low. Even if some consumers have strong willingness to buy, it has not been transformed into actual behavior[1]. Therefore, in order to effectively practice green consumption, it is very important to explore the internal influencing factors of consumers green purchase behavior.

Because green consumption has both costs and benefits, its potential motivation may lie in consumers perceived benefits. Although perceived benefits has been widely used to predict customers purchase behavior, it needs further research in the field of green consumption[2]. On the one hand, most studies only consider its mediating effect in the green purchase model, and rarely study it as an antecedent variable of green purchase attitude; On the other hand, most of them only take perceived value as a single variable to consider its impact on green purchase. Perceived benefits is a multi-dimensional variable, including perceived benefits and perceived risk. It emphasizes the balance between benefits and risks when consumers make purchase decisions. Specifically, based on the principle of value maximization, when implementing the purchase behavior, consumers will weigh the perceived benefits and perceived risks of green products, and further make the most favorable choice according to the weighed value. In addition, perceived value focuses on the consumer decision-making perspective. Therefore, it is of great significance to explore the real motivation of green purchase behavior from the perspective of consumer perceived value. In addition, due to the inconsistent economic development in different regions of China, consumers' purchasing power and purchasing environment are also uneven. In view of this, this paper takes the perceived income and perceived risk as the antecedent variables of consumers green purchase attitude, introduces the city level as the regulating variable, and uses the structural equation model to empirically analyze the influencing factors of consumers green purchase behavior in China, in order to provide a new research perspective for green purchase behavior, It also provides some enlightenment and reference for promoting green consumption.

\section{Theoretical Basis and Model Construction}

Perceived value plays an important role in the study of consumption behavior. Originally proposed by Zeithaml, it refers to the expected return before the behavior and the potential loss after the behavior, so it includes two antecedent variables: perceived return and perceived risk. Perceived benefit is perceived value, and the pre judgment of the potential loss of their own purchase behavior is perceived risk. When consumers produce purchase behavior, they will make a trade-off choice between value maximization and risk minimization. Moreover, many scholars have incorporated perceived benefits and perceived risks into the research model of green consumption behavior. For example, Chen Kai and others believe that perceived values and perceived risks have a significant impact on the purchase intention of new energy vehicles[3]; Based on this theory, Li et al. Studied agricultural 
green production intention through structural equation model, and found that perceived value and perceived risk have a significant impact on agricultural green production intention, and perceived value plays a decisive role[4]. It can be seen that consumers individual perceived benefits and perceived risk are important factors affecting green purchase decision-making. In addition, scholars Yang Xianchuan and Zhang Lei pointed out that different cities will lead to significant differences in residents low-carbon ideas, and the adjustment effect of urban level needs to be considered[5]. Therefore, based on the income risk analysis model, this paper comprehensively explores the influencing factors of consumers green purchase behavior from the perspective of income risk tradeoff. Figure 1 shows the conceptual model of influencing factors of consumers green purchase behavior under the perceived benefit risk trade-off.

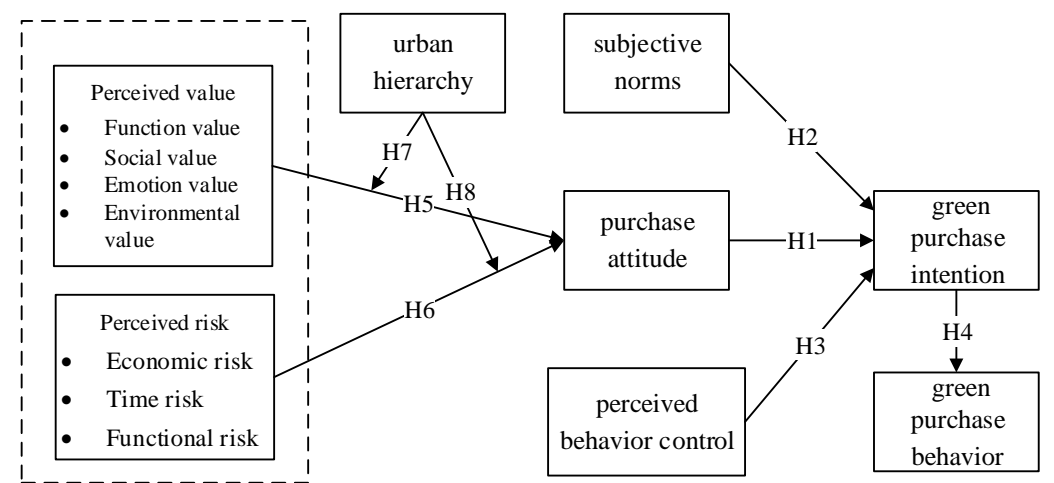

Figure 1: The model of green purchasing behavior under consumer benefit-risk balance

\section{Concept Definition and Research Hypothesis}

\subsection{Green Purchase Behavior Based on Planned Behavior Theory}

Planned behavior theory has been widely used to study behavior intention and actual behavior[6]. The front-end influencing factors are attitude, subjective norms and perceived behavior control. Scholars' research on the theory of planned behavior is roughly divided into two parts. One is to verify the effectiveness of the theory in exploring consumers green purchase behavior and willingness. For example, Rezai et al. Studied that Malaysian consumers positive purchase intention of green food is affected by attitude[7], subjective norms and perceived behavior control; Teng et al. Studied the decision-making process of consumers on green hotels[8]. The second is to take the extended planned behavior theory as the research model and seek new explanatory variables to explore its application in the field of green consumption. For example, Raukov introduced consumer innovation into planned behavior theory[9]; Maichum et al. Pointed out that environmental knowledge and environmental concern positively affect green purchase intention through attitude, subjective norms and perceived behavior control[10].

Therefore, consumersgreen purchase intention will be affected by attitude, subjective norms and perceived behavior control. When consumers hold a positive attitude towards green products, their purchase intention will be stronger; when there is a high consistency between green purchase intention and subjective norms, consumers will also have a high tendency to green products; In addition, when consumers make purchase decisions, they will evaluate their difficulty. If they feel the less obstacles, they are more likely to implement green purchase. Based on this, the following assumptions are put forward:

H1: consumers green purchase attitude has a positive impact on green purchase intention.
$\mathrm{H} 2$ : consumers subjective norms have a positive impact on green purchase intention.

H3: consumer perceived behavior control has a positive impact on green purchase intention.

H4: consumers purchase intention has a positive impact on green purchase behavior.

\subsection{The Influence of Perceived Value on Green Purchase Attitude}

Perceived benefit is the perceived value of consumers. Scholar Ducker first proposed perceived value. He believes that the core of enterprises is to meet consumer needs and provide value. After that, scholars further study the definition and dimension of perceived value. For example, from the perspective of consumers, Zeithaml believes that perceived benefit is the comprehensive evaluation of products after the balance between customers perceived benefits and perceived costs[11]. In addition, scholars have different dimensions of perceived value, among which the most classic is Sheth's five-dimensional division method, including functional value, emotional value, cognitive value, social value and conditional value[12]. Biswas and Roy put forward four value dimensions: value for money, social value, conditional value and cognitive value[13]; Based on the product life cycle theory, Chinese scholars Yang Xiaoyan proposed the important concept of green value, which expanded the dimension of perceived value[14]. It can be seen that under different purchase objects and purchase environments, the dimension composition of consumers perceived value will also change.

Based on Sheth and Zhang's perception measurement model, this paper divides perceived value into four dimensions: functional value, social value, emotional value and environmental value[15]. Functional value refers to consumers subjective evaluation of the quality, function and natural attributes of green products when purchasing and using green products. Product functional value is the main driving factor to decide whether consumers buy, and it has a significant impact on consumers green purchase intention[16], and attitude is an important antecedent variable of consumers 
green purchase intention. Therefore, functional value may have a significant impact on green purchase attitude. Social value is a measure of social benefits in the process of purchasing and using green products, such as obtaining recognition from others and establishing a good image. Sheth and others believe that social value has an important impact on consumers purchase behavior. In most cases, consumers hope to shape their positive image by purchasing a certain product. Therefore, when consumers conduct green purchase, they can get respect, praise or higher social reputation from others. The stronger their attitude towards green purchase, the more likely they are to implement the behavior. Emotional value is defined as the emotional utility from green products or services. Specifically, it is a sense of pleasure and pride when consumers buy green. When consumers make purchase decisions, they are usually affected by their emotions, such as pleasure, comfort, rest assured and worry. The advanced functions or technologies of green products will bring users a better experience and make consumers happy. Therefore, the higher the emotional value perceived by consumers, the more positive the attitude of green purchase will be. Environmental value refers to the effectiveness of green products in reducing environmental pollution and improving consumers awareness of environmental protection. Similar to emotional value, it is the value that consumers feel beneficial to the environment when they make green purchases. Environmental value is a kind of altruistic value, which can meet consumers pursuit of ecological value. When consumers pursuit is satisfied, their attitude towards buying green products has also become very positive. Based on this, the following assumptions are put forward:

H5: perceived value has an impact on consumers green purchase attitude.

H5a: functional value has a positive impact on consumers green purchase attitude.

H5B: social value has a positive impact on consumers green purchase attitude.

H5c: emotional value positively affects consumers green purchase attitude.

H5d: environmental value has a positive impact on consumers green purchase attitude.

\subsection{The Impact of Perceived Risk on Green Purchase Attitude}

Perceived risk was first proposed by scholar Bauer[17], which means that the result is uncertain because all situations cannot be predicted. Subsequently, Cox further defined perceived risk as a function of the following two factors: first, the possibility that consumers feel adverse consequences before implementing the purchase behavior[18]; The second is the loss of consumers individual subjective feeling after the purchase behavior. Perceived risk has different dimensions. For example, Jacoby \& Kaplan divided perceived risk into psychological risk, financial risk, physical risk, social risk, performance risk and time risk[19]; In studying the purchase intention of new energy vehicles, Chen Kai and others divided the perceived risk into financial risk, physical risk, time risk and functional risk. Considering that the research object of this paper is green products, based on the research results of Jacoby and Chen Kai, the perceived risk is divided into three dimensions: economic risk, time risk and functional risk.
Economic risk, or financial risk, refers to the money loss that may be brought to consumers by purchasing green products. For example, the incomplete subsidy policy for green products leads to consumers spending additional expenses. The time consumed by consumers to understand the performance and attributes of green products is the time risk perceived by consumers. Functional risk is the perception of the performance uncertainty of green products. Green products are still in the promotion stage in China, and most consumers still doubt their functional attributes. This uncertainty will obviously hinder the generation of green purchase behavior. Moreover, scholars have confirmed in the fields of organic food and new energy vehicles that the higher the perceived risk of consumers, the lower the purchase intention. Based on this, the following assumptions are put forward:

H6: perceived risk has an impact on consumers green purchase attitude.

H6a: economic risk negatively affects consumers green purchase attitude.

H6b: time risk negatively affects consumers green purchase attitude.

H6c: functional risk negatively affects consumers green purchase attitude.

\subsection{Regulation of Urban Hierarchy}

Since the reform and opening up, the imbalance of economic development among regions has become increasingly prominent, resulting in differences in consumers consumption habits and environment in different regions. Some scholars have pointed out that the consumption behavior of residents in different levels of cities presents temporal and spatial differences. Brotosusilo \& Handayani analyzed the data and concluded that the proenvironmental behavior of urban residents is also different with different regions and economic classes[20]. In addition, there will be significant differences between consumers sense of environmental responsibility and the government awareness of environmental protection. In view of this, this paper introduces the variable of city grade to explore whether there is a regulatory effect between consumers perceived benefits, perceived risk and green purchase attitude. The following assumptions are made:

H7: urban hierarchy has a moderating effect between perceived value and green purchase attitude.

H7a: urban hierarchy has a moderating effect between functional value and green purchase attitude.

H7b: urban hierarchy has a moderating effect between social value and green purchase attitude.

H7c: urban hierarchy has a moderating effect between emotional value and green purchase attitude.

H7d: urban hierarchy has a moderating effect between environmental value and green purchase attitude.

H8: urban hierarchy has a moderating effect between perceived risk and green purchase attitude.

H8a: urban hierarchy has a moderating effect between economic risk and green purchase attitude.

H8b: urban hierarchy has a moderating effect between time risk and green purchase attitude.

H8c: urban hierarchy has a moderating effect between functional risk and green purchase attitude. 


\section{Materials and Research Methods}

\subsection{Sample Selection and Data Collection}

Questionnaire survey was used to collect data. Firstly, based on the research model of this paper, a questionnaire is set up for the specific research content of this paper; Then, through the pre survey, the structure of the questionnaire is adjusted to obtain the formal questionnaire; Finally, the online questionnaire is distributed through social platforms such as Wechat, QQ and microblog. Questionnaires are sent by family members and friends to their colleagues and friends to improve data quality and reliability. A total of 500 invitations were sent out, 321 questionnaires were recovered, 22 questionnaires with the same answers to the main variables and 22 questionnaires with short answer time compared with the rest were deleted, and a total of 299 valid questionnaires $(93.1 \%)$ were obtained. The sample structure is shown in Table 1.

Table 1: Descriptive statistical characteristics of samples

\begin{tabular}{cccc}
\hline Variable & Item & Number & Percentage(\%) \\
\hline \multirow{2}{*}{ Gender } & male & 160 & 53.5 \\
& female & 139 & 46.5 \\
Age & $18-25$ & 253 & 84.6 \\
& $26-30$ & 19 & 6.4 \\
& $31-40$ & 12 & 4.0 \\
Educati & High school or technical secondary & 15 & 5.0 \\
on level & Junior high school and below & 10 & 3.3 \\
& Bachelor degree or junior college & 205 & 5.4 \\
& Master degree or above & 68 & 68.6 \\
Monthly & Less than 2000 yuan & 159 & 22.7 \\
income & 2001-4000 yuan & 58 & 53.2 \\
& 4001-8000 yuan & 55 & 19.4 \\
& $8001-10000$ yuan & 8 & 2.4 \\
Resident & 10001 yuan and above & 19 & 6.4 \\
ial city & frontline & 74 & 24.8 \\
& second line-an advisory post & 105 & 35.1 \\
& Three lines & 59 & 19.7 \\
& Four wire and below & 61 & 20.4 \\
\hline
\end{tabular}

It can be seen from table 1 that most respondents live in second tier cities and above in China, accounting for more than $50 \%$, indicating that the sample object has certain economic strength and has more extensive contact with green products. In terms of gender distribution, the ratio of men to women is $1.15: 1$, which is not much different from the current gender ratio of $1.07: 1$ in China. The age group is mainly between 18 and 25 years old, indicating that the sample is relatively young and has a strong ability to accept new things. The education level of the subjects is mostly undergraduate education, accounting for $68.6 \%$, indicating that the overall education level of the sample is high, and the monthly income level is concentrated below 2000-4000 yuan. Although the income level of the subjects is not high, their long-term residence is in China's economically developed areas. Combined with the purpose of investigation and research, this has no special impact on the research problems of this paper. In general, the demographic characteristics of the survey samples on consumers green product purchase behavior are basically consistent with the research objectives.

\subsection{Questionnaire Formulation}

The questionnaire consists of two parts: one is the demographic information of the subjects; The second is the measurement of the main variables of the research model. The questionnaire adopts the 5-point Likert scale. 1-5 respectively indicate very disagree, disagree, general, agree and very agree. In order to ensure the reliability of the data, the items of all variables strictly refer to the maturity scale and are revised in combination with the research content of this paper. Among them, the measurement of functional value, social value, emotional value and environmental value mainly refers to the scale developed by Khan and Mohsin[21], Yang Xiaoyan and Zhou Yijin; Perceived risk mainly refers to the scale of Wang Ying et al; The variables of green purchase attitude, willingness and behavior refer to the scale of Zhang et al; These scales have been used and confirmed in many empirical studies, so they have high reliability and content validity[22].

\subsection{Research Method}

This study mainly analyzes the questionnaire data through structural equation model. Firstly, SPSS 22.0 analyze the reliability and validity of the questionnaire data to test the reliability of the questionnaire; Secondly, Amos 22.0 was used for confirmatory factor analysis to test whether the scale has high convergent validity; Finally, the main effect is tested by constructing a structural equation model to verify whether the theoretical model and related assumptions are correct.

\section{Result Analysis}

\subsection{Reliability and Validity Analysis}

Structural equation model includes measurement model and structural model. In order to evaluate the measurement model, the reliability, convergence and differential validity of the model should be checked. Reliability refers to the internal consistency between different measurement items of a building, usually Cronbach' $\alpha$ Verify reliability, this value should exceed 0.7 [23]. Because the maturity scale referred to in this paper has content validity, confirmatory factor analysis is used to test the convergent validity and differential validity of the data. The results show that Cronbach's $\alpha$ of all variables such as functional value, social value, emotional value, environmental value, economic risk, time risk, functional risk, attitude, willingness and behavior And combination reliability are greater than 0.7 (Table 2), which indicates that the data has good reliability. At the same time, the factor load values of all items are greater than 0.6 , and the average extracted variation (AVE) of each variable is greater than 0.6, which means that the sample data has good convergence validity. The arithmetic square root of ave value corresponding to the construct is higher than the correlation coefficient between latent variables (Table 3), indicating that there is good discriminant validity between constructs.

\subsection{Test and Analysis of Structural Equation Model}

Amos 22.0 is used to test the model. The model fitting results are shown in Table 4. Except that GFI does not meet the ideal standard, all other indicators meet the requirements of the recommended value, and the difference between GFI of 0.801 and the ideal value of 0.9 is small. Therefore, it can be considered that the fitting effect between the hypothetical theoretical model and the observed data is good. 
Table 2: Results of the confirmatory factor analysis

\begin{tabular}{|c|c|c|c|c|c|}
\hline Construct & Item & Factor load & Cronbach's $\alpha$ & $\mathrm{CR}$ & AVE \\
\hline \multirow{3}{*}{ Functional value (FV) } & FV1 & 0.748 & \multirow{3}{*}{0.881} & \multirow{3}{*}{0.887} & \multirow{3}{*}{0.72} \\
\hline & FV2 & 0.881 & & & \\
\hline & FV3 & 0.917 & & & \\
\hline \multirow{3}{*}{ Social value (SV) } & SV1 & 0.892 & \multirow{3}{*}{0.932} & \multirow{3}{*}{0.933} & \multirow{3}{*}{0.823} \\
\hline & SV2 & 0.932 & & & \\
\hline & SV3 & 0.897 & & & \\
\hline \multirow{4}{*}{ Emotional value (EV) } & EV1 & 0.851 & \multirow{3}{*}{0.906} & \multirow{4}{*}{0.908} & \multirow{4}{*}{0.766} \\
\hline & EV2 & 0.887 & & & \\
\hline & EV3 & 0.887 & & & \\
\hline & ENV1 & 0.915 & \multirow{3}{*}{0.933} & & \\
\hline \multirow[t]{3}{*}{ Environmental value (Env) } & ENV2 & 0.928 & & \multirow[t]{3}{*}{0.933} & \multirow[t]{3}{*}{0.823} \\
\hline & ENV3 & 0.878 & & & \\
\hline & ER1 & 0.784 & & & \\
\hline \multirow[t]{3}{*}{ Economic risk (ER) } & ER2 & 0.885 & \multirow[t]{3}{*}{0.887} & \multirow[t]{3}{*}{0.889} & \multirow[t]{3}{*}{0.72} \\
\hline & ER3 & 0.888 & & & \\
\hline & TR1 & 0.816 & & & \\
\hline \multirow[t]{3}{*}{ Time risk (TR) } & TR2 & 0.794 & \multirow[t]{3}{*}{0.857} & \multirow[t]{3}{*}{0.859} & \multirow[t]{3}{*}{0.67} \\
\hline & TR3 & 0.846 & & & \\
\hline & FR1 & 0.855 & & & \\
\hline \multirow[t]{3}{*}{ Functional risk (FR) } & FR2 & 0.879 & 0.909 & 0.910 & 0.771 \\
\hline & FR3 & 0.900 & & & \\
\hline & ATT1 & 0.845 & & & \\
\hline & ATT2 & 0.887 & & & \\
\hline Attitude (ATT) & ATT3 & 0.927 & 0.927 & 0.935 & 0.783 \\
\hline & ATT4 & 0.879 & & & \\
\hline & SN1 & 0.814 & & & \\
\hline & SN2 & 0.750 & & & \\
\hline Subjective norm (SN) & SN3 & 0.808 & 0.872 & 0.892 & 0.675 \\
\hline & SN4 & 0.906 & & & \\
\hline & INT1 & 0.835 & & & \\
\hline & INT2 & 0.743 & & & \\
\hline Intention(int) & INT3 & 0.904 & 0.906 & 0.908 & 0.713 \\
\hline & INT4 & 0.887 & & & \\
\hline & $\mathrm{PC} 1$ & 0.820 & & & \\
\hline Dorcaind haviorontel (DC) & $\mathrm{PC} 2$ & 0.757 & 0944 & 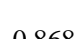 & 06023 \\
\hline Perceived behavior control (PC) & PC3 & 0.863 & 0.844 & 0.868 & 0.623 \\
\hline & $\mathrm{PC} 4$ & 0.707 & & & \\
\hline & BEH1 & 0.853 & & & \\
\hline & $\mathrm{BEH} 2$ & 0.816 & & & \\
\hline Behavior (beh) & $\mathrm{BEH} 3$ & 0.756 & 0.879 & 0.894 & 0.680 \\
\hline & BEH4 & 0.868 & & & \\
\hline
\end{tabular}

Table 3: Results of discriminant validity

\begin{tabular}{|c|c|c|c|c|c|c|c|c|c|c|c|c|}
\hline & $\mathrm{FV}$ & SV & EV & ENV & ER & TR & FR & ATT & SN & INT & $\mathrm{PC}$ & $\mathrm{BEH}$ \\
\hline $\mathrm{FV}$ & 0.852 & & & & & & & & & & & \\
\hline SV & $0.696^{* *}$ & 0.907 & & & & & & & & & & \\
\hline EV & $0.730 * *$ & $0.841 * *$ & 0.875 & & & & & & & & & \\
\hline ENV & $0.647 * *$ & $0.669 * *$ & $0.740 * *$ & 0.907 & & & & & & & & \\
\hline ER & $0.383 * *$ & $0.379 * *$ & $0.374 * *$ & $0.424 * *$ & 0.854 & & & & & & & \\
\hline TR & $0.436 * *$ & $0.451 * *$ & $0.404 * *$ & $0.400 * *$ & $0.712 * *$ & 0.819 & & & & & & \\
\hline FR & $0.381 * *$ & $0.349 * *$ & $0.369 * *$ & $0.464 * *$ & $0.643 * *$ & $0.696 * *$ & 0.878 & & & & & \\
\hline ATT & $0.633 * *$ & $0.636 * *$ & $0.716 * *$ & $0.741 * *$ & $0.451 * *$ & $0.498 * *$ & $0.552 * *$ & 0.885 & & & & \\
\hline SN & $0.626 * *$ & $0.587 * *$ & $0.653 * *$ & $0.557 * *$ & $0.470 * *$ & $0.579 * *$ & $0.467 * *$ & $0.713 * *$ & 0.822 & & & \\
\hline INT & $0.644 * *$ & $0.602 * *$ & $0.664 * *$ & $0.664 * *$ & $0.453 * *$ & $0.544 * *$ & $0.538 * *$ & $0.835^{* *}$ & $0.763 * *$ & 0.844 & & \\
\hline PC & $0.555 * *$ & $0.504 * *$ & $0.546^{* *} *$ & $0.613 * *$ & $0.498 * *$ & $0.584 * *$ & $0.615 * *$ & $0.742 * *$ & $0.668 * *$ & $0.723 * *$ & 0.789 & \\
\hline
\end{tabular}

Note: Diagonal bold value is the square root of ave; The lower triangle is the Pearson correlation coefficient between variables $* \mathrm{P}<0.05$, ${ }^{*} * \mathrm{P}<0.01$.

Table 4: Evaluation criteria of model fitness

\begin{tabular}{|c|c|c|c|c|c|c|c|c|c|}
\hline index & $\lambda 2 / \mathrm{DF}$ & GFI & RMR & RMSEA & PNFI & PGFI & IFI & CFI & TLI \\
\hline Actual value & 2.438 & 0.801 & 0.044 & 0.069 & 0.804 & 0.678 & 0.927 & 0.927 & 0.927 \\
\hline evaluation criterion & $<3$ & $>0.9$ & $<0.08$ & $<0.08$ & $>0.5$ & $>0.5$ & $>0.9$ & $>0.9$ & $>0.9$ \\
\hline
\end{tabular}

The relationship between each latent variable is tested through the structural equation model, and the results are shown in Table 5. The standardized path coefficients of consumers green purchase attitude, subjective norms and perceived behavior control on purchase intention are $0.829,0.220$ and 0.197 respectively, which are significant at the level of $\mathrm{P}<0.001$ or $\mathrm{P}<0.05$. Therefore, it is assumed that $\mathrm{H} 1, \mathrm{H} 2$ and $\mathrm{H} 3$ pass the test. The path coefficient from consumers green 
purchase intention to actual behavior is 0.913 , which is significant, assuming that $\mathrm{H} 4$ is true.

The path coefficient of consumers perceived value to green purchase attitude is 0.689 , and the functional value FV $(\beta=0.823, \quad \mathrm{P}<0.001)$, social value $(\beta=0.857, \quad \mathrm{P}<0.001)$, emotional value $(\beta=0.972, P<0.001)$, environmental value $(\beta=0.835, P<0.001)$ has significant path coefficients on consumers purchase attitude, so it is assumed that $5,5 \mathrm{~A}, 5 \mathrm{~b}$, $5 \mathrm{C}$ and $5 \mathrm{D}$ are true. Perceived risk has a significant impact on green purchase attitude $(\beta=0.24, \mathrm{P}<0.001)$, so H6 is assumed to be true. Economic risk, time risk and functional risk have a significant positive correlation with purchase attitude, which is contrary to the original hypothesis, so h6a, h6b and h6c are not tenable.

Table 5: Path coefficients of the structural model

\begin{tabular}{|c|c|c|c|c|c|}
\hline Path & S.E. & Estimate & T-value & Hypotheses & Result \\
\hline $\mathrm{ATT} \rightarrow \mathrm{INT}$ & 0.074 & 0.829 & $10.678 * * *$ & $\mathrm{H} 1$ & Support \\
\hline $\mathrm{SN} \rightarrow \mathrm{INT}$ & 0.060 & 0.220 & $2.979 * *$ & $\mathrm{H} 2$ & Support \\
\hline $\mathrm{PC} \rightarrow \mathrm{INT}$ & 0.040 & 0.197 & $5.195^{* * *}$ & $\mathrm{H} 3$ & Support \\
\hline $\mathrm{INT} \rightarrow \mathrm{BEH}$ & 0.059 & 0.913 & $15.558 * * *$ & $\mathrm{H} 4$ & Support \\
\hline VALUE $\rightarrow$ ATT & 0.078 & 0.689 & $10.832 * * *$ & $\mathrm{H} 5$ & Support \\
\hline $\mathrm{FV} \rightarrow \mathrm{VALUE}$ & 0.085 & 0.823 & $13.444 * * *$ & H5a & Support \\
\hline $\mathrm{SV} \rightarrow \mathrm{VALUE}$ & 0.079 & 0.857 & $14.086^{* * * *}$ & $\mathrm{H} 5 \mathrm{~b}$ & Support \\
\hline $\mathrm{EV} \rightarrow \mathrm{VALUE}$ & 0.075 & 0.972 & $15.787 * * *$ & $\mathrm{H} 5 \mathrm{c}$ & Support \\
\hline $\mathrm{ENV} \rightarrow \mathrm{VALUE}$ & 0.065 & 0.835 & $13.444 * * *$ & H5d & Support \\
\hline $\mathrm{RISK} \rightarrow \mathrm{ATT}$ & 0.056 & 0.240 & $4.656^{* * *}$ & H6 & Support \\
\hline $\mathrm{ER} \rightarrow \mathrm{RISK}$ & 0.072 & 0.840 & $13.240 * * *$ & H6a & Not support \\
\hline $\mathrm{TR} \rightarrow \mathrm{RISK}$ & 0.083 & 0.949 & $13.445 * * *$ & $\mathrm{H} 6 \mathrm{~b}$ & Not support \\
\hline $\mathrm{FR} \rightarrow \mathrm{RISK}$ & 0.067 & 0.845 & $13.445 * * *$ & $\mathrm{H} 6 \mathrm{c}$ & Not support \\
\hline
\end{tabular}

\subsection{Regulatory Effect Analysis}

Because city grade is a category variable, the grouping regression method is used to explore whether different city grades have a regulatory effect on consumers perceived value and purchase attitude. If the regression coefficient is significant and different, it indicates that there is a regulatory effect.

Table 6: Results of group regression

\begin{tabular}{ccccc}
\hline & frontline & second line & Three lines & Four wire and below \\
\hline FV & $0.741 * * *$ & $0.499 * * *$ & $0.654 * * *$ & $0.664 * * *$ \\
SV & $0.666 * * *$ & $0.567 * * *$ & $0.622 * * *$ & $0.720 * * *$ \\
EV & $0.651 * * *$ & $0.664 * * *$ & $0.749 * * *$ & $0.834 * * *$ \\
ENV & $0.789 * * *$ & $0.624 * * *$ & $0.789^{* * *}$ & $0.780 * * *$ \\
ER & $0.443 * * *$ & $0.399 * * *$ & $0.536 * * *$ & $0.424 * * *$ \\
TR & $0.507 * * *$ & $0.479 * * *$ & $0.622 * * *$ & $0.364 * * *$ \\
FR & $0.515 * * *$ & $0.550 * * *$ & $0.633 * * *$ & $0.486 * * *$ \\
N & 74 & 104 & 59 & 62 \\
\hline
\end{tabular}

Dependent variable: ATT, $* * * \mathrm{P}<0.001$.

It can be seen from table 6 that consumers in first tier cities pay more attention to the functional value of green products, and their regression coefficient is the largest; For social value and emotional value, consumers in the fourth tier cities and below have the largest regression coefficient. The reason is that consumers in the fourth tier cities and below generally have lower cultural level than those in the first and second tier cities, and pay more attention to the external evaluation of themselves, resulting in these consumers paying more attention to the social value and emotional value brought by purchasing green products; There is not much difference in environmental value among different urban levels, which means that the regulatory effect of urban level on environmental value and purchase attitude of green products is not significant. Similarly, by exploring whether the city level has an impact on consumers perceived risk and purchase attitude, it is concluded that there is little difference in the coefficient of economic risk, which may be due to the younger sample, because contemporary young people are more willing to choose a healthy lifestyle, even if there are large economic differences among cities, But it does not affect consumers green purchase attitude; For time risk, it can be seen that the regression coefficients of first tier, second tier and third tier cities are greater than those of fourth tier cities and below, and the maximum difference is 0.258 , indicating that consumers in fourth tier cities and below do not have a strong sense of time, which is consistent with the actual situation; Among the functional risks, consumers in the third tier cities have the largest regression coefficient. The possible reason is that although consumers in the third tier cities have strong economic strength compared with consumers in the fourth tier cities and below, they can not reach the high economic level of consumers in the first and second tier cities. Therefore, such consumers pay more attention to the functional value of green products. To sum up, assumptions $7 \mathrm{a}, 7 \mathrm{~b}, 7 \mathrm{C}, 8 \mathrm{~b}$ and $8 \mathrm{C}$ are true, and assumptions $7 \mathrm{~d}$ and $8 \mathrm{~A}$ are not true.

\section{Discuss}

Based on the original framework of planned behavior theory, combined with the income risk analysis model, this paper analyzes and verifies consumers green purchase behavior in the form of questionnaire, and creatively adds the adjustment variable of city grade to explore whether there are differences in green purchase among different cities. The empirical results show that both perceived value and perceived risk have an impact on consumers green purchase attitude, and the regulatory effect of city level has been partially confirmed.

(1) Consumers perceived value has a significant impact on green purchase attitude. Among the four drivers of perceived value, emotional value and social value are more driven, while functional value and environmental value are relatively less driven. This is because consumers concept and efficacy of green products are relatively vague, and the survey sample is relatively young, so young consumers can be valued more is the emotional value brought by the product.

(2) Consumer perceived risk has a significant impact on green purchase attitude. However, the coefficient between perceived risk and purchase attitude is positive, that is, the greater the risk perceived by consumers, the more likely they are to buy green products. Among the three driving factors of 
perceived risk, time risk is the most significant. Although the conclusion of positive correlation between the two is inconsistent with our actual situation, considering Due to the particularity of the sample structure, the proportion of young and middle-aged subjects is as high as $84.6 \%$. The consumption psychology of young consumers who like novelty largely leads to this conclusion. In addition, despite the high risk perceived by consumers, with the publicity of green products, public consumers also have a high degree of recognition for green products, coupled with government subsidies, so their green purchase attitude is also high.

(3) in adjusting the adjustment of city level, the regulatory effect of other variables is significant except for the moderating effect of environmental value and economic risk. The possible reason is that the global environment has been seriously damaged, and the outbreak of global COVID-19 in 2020 has made Chinese people gradually realize the importance of protecting the ecological environment. Health is also particularly important. Therefore, whether it is the first tier cities with developed economy or the fourth and fifth tier cities with relatively backward economy, consumers environmental value perception is relatively strong, while their economic risk perception is relatively weak. In conclusion, the moderating effect of city level on environmental value, economic risk and green purchase attitude is not significant.

\section{References}

[1] Li Chuang, Shao Ying. How to improve the consistency of intention and behavior in the context of green consumption?-Empirical test based on regulatory effect[J]. Resources and environment in arid areas, 2020, 34 (08): 19-26

[2] Gallarza M G, Gil-Saura I, Holbrook M B. The value of value: Further excursions on the meaning and role of customer value $[\mathrm{J}]$. Journal of Consumer Behaviour, 2011, 10(4): 179-191.

[3] Chen Kai, Gu Rong, Hu Jing. Research on purchase intention of new energy vehicles based on perceived return perceived risk framework[J]Journal of Nanjing University of Technology (Social Science Edition), 2019, 18 (02): 61-70+112

[4] Li M, Wang J, Zhao P, et al. Factors affecting the willingness of agricultural green production from the perspective of farmers perceptions[J]. Science of The Total Environment, 2020, 738:140289.

[5] Yang Xianchuan, Zhang Lei. Research on the impact of consumption value and social situation on urban residents low-carbon consumption intention[J]. Research on technology, economy and management, 2018 (08): 21-26

[6] Shi H, Wang S, Zhao D. Exploring urban residen's vehicular PM2.5 reduction behavior intention: An application of the extended theory of planned behavior[J]. Journal of Cleaner Production, 2017, 147: 603-613.

[7] Rezai G, Mohamed Z A, Shamsudin M N, et al. Demographic and attitudinal variables associated with consumers intention to purchase green produced foods in Malaysia[J]. International Journal of Innovation Management \& Technology, 2016.
[8] Teng Y M, Wu K S, Liu H H. Integrating Altruism and the Theory of Planned Behavior to Predict Patronage Intention of a Green Hotel[J]. Journal of Hospitality \& Tourism Research, 2013, 39(3).

[9] Raukov. Research on the influence mechanism of consumer innovation on green consumption behavior[J]. Nankai Management Review, 2013, 16 (04): 106-113+132.

[10] Kamonthip M, Surakiat P, Peng K C. Application of the Extended Theory of Planned Behavior Model to Investigate Purchase Intention of Green Products among Thai Consumers[J]. Sustainability, 2016, 8(10): 1077.

[11] Zeithaml V A. Consumer Perceptions of Price, Quality, and Value: A Means-End Model and Synthesis of Evidence[J]. Journal of Marketing, 1988, 52(3): 2-22.

[12] Sheth J N, Newman B I, Gross B L. Why we buy what we buy: A theory of consumption values[J]. Journal of Business Research, 1991, 22(2): 159-170.

[13] Biswas A, Roy M. Leveraging factors for sustained green consumption behavior based on consumption value perceptions: testing the structural model[J]. Journal of Cleaner Production, 2015, 95: 332-340.

[14] Yang Xiaoyan, Zhou Yijin. Green value: a new dimension of customer perceived value $[\mathrm{J}]$. China Industrial Economy, 2006 (07): 110-116

[15] Zhang Y, Xiao C, Zhou G. Willingness to pay a price premium for energy-saving appliances: Role of perceived value and energy efficiency labeling $[\mathrm{J}]$. Journal of Cleaner Production, 2019, 242: 118555.

[16] Zhang Xuemu, Wang Xining. The impact of ecological labels on the purchase intention of green products -mediated by consumers perceived value $[\mathrm{J}]$. Ecological Economy, 2019, 35 (01): 59-64

[17] Bauer R A. Consumer Behavior as Risk Taking[M]. Hancock R S. Dynamic Marketing for A Changing World. Chicago: American Marketing Association, 1960.

[18] Cox D F. Risk Taking and Information Handling in Consumer Behavior[M]. Boston: Harvard University Press, 1967.

[19] Jacoby J, Kaplan L B. The Components of Perceived Risk[J]. Advances in Consumer Research. Association for Consumer Research (U.S.), 1972, 3(3).

[20] Brotosusilo A, Handayani D. Dataset on waste management behaviors of urban citizens in large cities of Indonesia[J]. Data in Brief, 2020, 32: 106053.

[21] Khan S N, Mohsin M. The Power of Emotional Value: Exploring the Effects of Values on Green Product Consumer Choice Behavior[J]. Journal of Cleaner Production, 2017, 150(MAY1): 65-74.

[22] Wang Ying, Li Ying. An empirical study on consumers purchase intention of new energy vehicles based on perceived risk and human involvement[J]. Mathematical statistics and management, 2013, 32 (05): 863-872

[23] Straub D, Gefen D. Validation Guidelines for IS Positivist Research[J]. Communications of the Association for Information Systems, 2004, 3. 